\title{
Frailty syndrome in the community- dwelling elderly with osteoarthritis
}

\author{
Rita de Cássia Corrêa Miguel ${ }^{1}$, Rosângela Corrêa Dias², João Marcos Domingues Dias²,
} Silvia Lanziotti Azevedo da Silva ${ }^{3}$, Paulo Roberto Menicucci Filho ${ }^{4}$, Tatiana Moreira S. Ribeiro ${ }^{5}$

\begin{abstract}
Objective: To characterize and compare community-dwelling elderly with knee and/or hip osteoarthritis (OA), focusing on the frailty syndrome. Method: Cross-sectional study of the elderly with knee and/or hip OA, using a subsample from the study of frailty in the Brazilian elderly (FIBRA), assessing the following: sociodemographic characteristics, comorbidity, medications, depression, anthropomorphic data, falls, pain, stiffness, physical function, and frailty. The subjective assessment of health was also performed. Results: The final sample comprised 58 elderly (mean age, $74 \pm$ 5.5 years) as follows: 17 (29.31\%) non-frail, 28 (48.28\%) pre-frail, and 13 (22.41\%) frail. The frail elderly received more medications than the non-frail ones $(7.00 \pm 2.00$ and $4.00 \pm 2.00$, respectively; $\mathrm{P}=0.001)$. The mean Body Mass Index was lower in the non-frail elderly as compared with those of the pre-frail and frail ones $\left(27.00 \pm 4.50 \mathrm{~kg} / \mathrm{m}^{2}\right.$, $30.00 \pm 4.00 \mathrm{~kg} / \mathrm{m}^{2}$, and $34.00 \pm 8.00 \mathrm{~kg} / \mathrm{m}^{2}$, respectively; $\left.\mathrm{P}=0.018\right)$. Depression was more prevalent in the frail group. Compared to the previous year, there was a difference in the health status of the groups as follows: $64.3 \%$ of the pre-frail elderly and $46.2 \%$ of the frail ones believed their health deteriorated, and $52.9 \%$ of the non-frail elderly considered that their health status remained unchanged $(\mathrm{P}=0.016)$. When comparing the current physical activity levels with those of the previous year, the pre-frail and frail elderly reported a worsening $(\mathrm{P}=0.010)$. Regarding physical function and fall-related self-efficacy, the frail elderly were worse than the others $(\mathrm{P}=0.023$ and 0.017 , respectively). There were no significant differences between the groups for the remaining items analyzed. Conclusion: The elderly with OA and frailty use more medications, are more obese and depressed, have a poorer perception of their own health and of their level of activity as compared with that of the previous year, have a worse fall-related self-efficacy, and worse physical function.
\end{abstract}

Keywords: frail elderly, knee osteoarthritis, hip osteoarthritis, disable people.

(C) 2012 Elsevier Editora Ltda. All rights reserved.

\section{INTRODUCTION}

The increase in the population's life expectancy has a significant impact on health conditions, morbidity and functional limitations among the elderly. ${ }^{1}$ Osteoarthritis (OA) is strongly associated with age and is the most common rheumatic disease, affecting approximately $16 \%$ of the Brazilian population. ${ }^{2-4}$ Of the large joints, knees and hips are the most often affected by OA. ${ }^{2}$ Its clinical manifestations vary and include pain, stiffness, reduction in muscle strength, joint instability, deformities, and gait changes. ${ }^{2,3}$ Such manifestations can lead to functional limitation, disability and falls. . $^{2,45}$

\footnotetext{
Received on 07/03/2011. Approved on 03/05/2012. The authors declare no conflict of interest. Financial Support: Universidade Federal de Minas Gerais. Ethics Committee: 0062.0.203.000-10.

School of Physical Education, Physical Therapy and Occupational Therapy, Universidade Federal de Minas Gerais - UFMG.

1. Master degree in Rehabilitation Sciences; Rheumatologist of the Hospital das Clínicas, UFMG; Preceptor of the Internal Medicine Residency, Hospital Júlia Kubitschek; Professor of the Medical School, Universidade José do Rosário Vellano

2. Physical therapist; Associate Professor, School of Physical Education, Physical Therapy and Occupational Therapy, UFMG

3. Physical therapist; Master degree in Rehabilitation Sciences

4. Radiologist, Axial Centro de Imagens

5. Undergraduate student of Physical Therapy, UFMG

Correspondence to: Rita de Cássia Corrêa Miguel. Escola de Educação Física. Av. Antônio Carlos, 6627 - $3^{\circ}$ andar - Unidade Administrativa II - Pampulha.
} CEP: 31270-901. Belo Horizonte, MG, Brasil. E-mail: ritacmiguel@yahoo.com.br 
Frailty is a distinct clinical syndrome in which there is a reduction in the body's physiological reserves and homeostatic capacity to resist to stressors, due to the cumulative decline of the physiological systems, comprising mainly sarcopenia, neuroendocrine dysregulation, and immune dysfunction. ${ }^{6-9}$ Fried et al. ${ }^{6}$ have proposed the operational definition of a frailty phenotype, which was used in the present study. Frail elderly are more susceptible to adverse outcomes, such as functional limitation, falls, institutionalization, hospitalization, and increased mortality. ${ }^{6}$

$\mathrm{OA}$ is considerably prevalent in studies about frailty, with which it has a significant association. ${ }^{10,11}$ Nevertheless, in addition to the isolated impact of frailty and OA on the functional capacity and quality of life of the elderly, ${ }^{4,6}$ no study characterizing the elderly with OA based on the frailty phenotype has been found in the databases assessed. Thus, this study aimed at characterizing community-dwelling elderly with knee and/or hip OA regarding sociodemographic, clinical, and functional aspects, with emphasis on the frailty syndrome.

\section{MATERIALS AND METHODS}

This cross-sectional observational study was approved by the Committee on Ethics and Research (0062.0.203.000-10). All participants provided written informed consent.

From the database of the study Perfis de Fragilidade em Idosos Brasileiros Residentes na Comunidade (Rede FIBRA, central area of the city of Belo Horizonte) with 607 community-dwelling elderly, all individuals who answered affirmatively to the question "Have you been diagnosed with arthritis or rheumatism by a physician?" (162 elderly) were selected for contact. The inclusion criteria were age over 65 years and meeting the American College of Rheumatology criteria for knee and/or hip OA., ${ }^{2,312}$ The exclusion criteria were: cognitive deficit identified in the Mini-mental State Examination, ${ }^{13}$ previous arthroplasty, diagnosis of systemic rheumatic diseases, impossibility to walk independently, and lack of handgrip strength.

The elderly diagnosed with, or suspected of having, knee and/or hip OA were invited to participate in the study and visited in their homes. During the visits, the clinical diagnosis of knee and/or hip OA was assessed and those who did not meet the criteria proposed in the study were excluded. Once the diagnosis of OA was confirmed, the WOMAC (Western Ontario and McMaster Universities) questionnaire, ${ }^{14}$ specific to assess pain, stiffness, and physical function domains in patients with knee and/or hip
OA, was applied. Then, the Rede FIBRA questionnaire, containing items that assess sociodemographic characteristics, comorbidities, perceived physical health, Body Mass Index (BMI), falls (self-reported and Falls Efficacy Scale-FES-I-Brasil, ${ }^{15}$ the later according to cut-off points defined by Camargos et al. ${ }^{15}$ and total score), and depression (self-reported and Geriatric Depression Scale-GDS), ${ }^{16}$ was used. In addition, that questionnaire contains questions and measures that allow the characterization of the elderly according to the frailty phenotype proposed by Fried et al., ${ }^{6}$ as follows: unintentional weight loss ( $\geq 4.5 \mathrm{~kg}$ ), self-reported exhaustion (assessed by use of the questions: "Have you felt you had to make an effort to deal with your usual chores?" and "Have you dropped many of your activities and interests?", the answers "frequently" or "always" to any of those questions scored one point), weak grip strength (assessed by use of the JAMAR dynamometer, and with the adoption of the cut-off points proposed by Fried ${ }^{6}$ and adjusted for gender and BMI), low physical activity (assessed by use of the Minnesota Leisure Time Activities Questionnaire, according to which, women with a week energy expenditure $<270 \mathrm{kcal}$ and men with a week energy expenditure $<383 \mathrm{kcal}$ were considered fragile for that item), and slow walking speed (time spent, in seconds, to cover a 4.6-m distance at a usual auto-selected speed; the cut-off points proposed by Fried ${ }^{6}$ and adjusted for gender and height were adopted). According to the number of those characteristics, the elderly were classified as frail, with at least three of those characteristics; pre-frail, with one or two; and non-frail, with none.

The elderly included in the study were invited to undergo radiography of the joints affected at a specialized clinic. The analyses were performed by the same examiner, who was unaware of the elderly's clinical data. Radiographic OA was classified according to the Kellgren-Lawrence grading system. ${ }^{17}$

\section{Statistical analysis}

The descriptive analysis of the data collected was performed. The chi-square test was used to assess the differences between the frailty levels for the categorical variables.

When the expected frequency was lower than five, Fisher exact test was used. The continuous variables were assessed by use of analysis of variance (ANOVA) with Tukey multiple comparisons, when data had a normal distribution. When the normality assumption was violated, the Kruskal-Wallis test was used with Mann-Whitney post-tests. All analyses were 
performed with the SPSS software, version 16.0, with $95 \%$ confidence $(\alpha=5 \%)$.

\section{RESULTS}

Of the 162 elderly selected, 12 (7.4\%) could not be contacted. Of the remaining 150, 37 (24.6\%) had other rheumatic diseases, $14(9.3 \%)$ denied the presence of rheumatism, and $99(66.6 \%)$ had symptoms of knee and/or hip OA. Of those 99 , nine $(9.09 \%)$ refused to participate, and the others were assessed. Nineteen elderly (19.2\%) were excluded, 13 of whom $(13.2 \%)$ due to arthroplasty, two $(2.0 \%)$ due to dementia, three (3.0\%) who could not walk independently, and one $(1 \%)$ who could not undergo the handgrip test.
Thus, 71 elderly, who met the clinical criteria for knee and/or hip OA, were included and assessed. Later, 13 of them $(18.3 \%)$ were excluded from the sample as follows: $10(14.08 \%)$ who refused to undergo radiography and three $(4.2 \%)$ who had no radiographic changes. Thus, the final analysis comprised 58 elderly: four (6.9\%) men and $54(93.1 \%)$ women.

Of the 58 elderly resulting from the final analysis, 17 (29.31\%) were classified as non-frail (NF), $28(48.28 \%)$ as pre-frail (PF), and $13(22.4 \%)$ as frail $(\mathrm{F})$. Table 1 shows the sociodemographic characteristics of that population. The mean age of the sample showed no significant difference in the three classes as follows: NF, $74 \pm 5$ years; PF, $73 \pm 6$ years; and $\mathrm{F}, 75 \pm 6$ years $(\mathrm{P}=0.606)$.

Table 1

Descriptive analysis of the total sample $(\mathrm{n}=58)$ and of the frailty groups, and difference between frailty groups

\begin{tabular}{|c|c|c|c|c|c|c|c|c|c|c|}
\hline \multirow{2}{*}{ Variable } & \multicolumn{2}{|c|}{ Total sample } & \multicolumn{2}{|c|}{ NF } & \multicolumn{2}{|c|}{ PF } & \multicolumn{2}{|c|}{$\mathbf{F}$} & \multirow{2}{*}{$\mathbf{P}$} & \multirow{2}{*}{ Test } \\
\hline & $\mathbf{n}$ & $\%$ & $\mathbf{n}$ & $\%$ & $\mathbf{n}$ & $\%$ & $n$ & $\%$ & & \\
\hline $\begin{array}{l}\text { Gender } \\
\text { Male } \\
\text { Female }\end{array}$ & $\begin{array}{r}4 \\
54\end{array}$ & $\begin{array}{r}6.9 \\
93.1\end{array}$ & $\begin{array}{r}2 \\
15\end{array}$ & $\begin{array}{l}11.8 \\
88.2\end{array}$ & $\begin{array}{r}2 \\
26\end{array}$ & $\begin{array}{r}7.1 \\
22.9\end{array}$ & $\begin{array}{r}0 \\
13\end{array}$ & $\begin{array}{r}0.0 \\
100.0\end{array}$ & 0.451 & Chi-square \\
\hline $\begin{array}{l}\text { Marital status } \\
\text { Married } \\
\text { Single } \\
\text { Divorced/separated } \\
\text { Widow(er) }\end{array}$ & $\begin{array}{r}22 \\
11 \\
3 \\
22\end{array}$ & $\begin{array}{r}37.9 \\
19.0 \\
5.2 \\
37.9\end{array}$ & $\begin{array}{l}5 \\
5 \\
1 \\
6\end{array}$ & $\begin{array}{r}29.5 \\
29.5 \\
5.9 \\
35.3\end{array}$ & $\begin{array}{r}11 \\
3 \\
2 \\
12\end{array}$ & $\begin{array}{r}39.3 \\
10.7 \\
7.1 \\
42.9\end{array}$ & $\begin{array}{l}6 \\
3 \\
0 \\
4\end{array}$ & $\begin{array}{r}46.2 \\
23.1 \\
0.0 \\
30.8\end{array}$ & 0.683 & Chi-square \\
\hline $\begin{array}{l}\text { Color/ethnicity } \\
\text { White } \\
\text { Black } \\
\text { Mixed heritage } \\
\text { or mulatto }\end{array}$ & $\begin{array}{r}34 \\
6 \\
18\end{array}$ & $\begin{array}{l}58.6 \\
10.4 \\
31.0\end{array}$ & $\begin{array}{l}9 \\
2 \\
6\end{array}$ & $\begin{array}{l}52.9 \\
11.8 \\
35.3\end{array}$ & $\begin{array}{r}17 \\
4 \\
7\end{array}$ & $\begin{array}{l}60.7 \\
14.3 \\
25.0\end{array}$ & $\begin{array}{l}8 \\
0 \\
5\end{array}$ & $\begin{array}{r}61.5 \\
0.0 \\
38.5\end{array}$ & 0.628 & Chi-square \\
\hline $\begin{array}{c}\text { Retired } \\
\text { Yes } \\
\text { No }\end{array}$ & $\begin{array}{l}42 \\
16\end{array}$ & $\begin{array}{l}72.4 \\
27.6\end{array}$ & $\begin{array}{r}12 \\
5\end{array}$ & $\begin{array}{l}70.6 \\
29.4\end{array}$ & $\begin{array}{r}20 \\
8\end{array}$ & $\begin{array}{l}71.4 \\
28.6\end{array}$ & $\begin{array}{r}10 \\
3\end{array}$ & $\begin{array}{l}76.9 \\
23.1\end{array}$ & 0.917 & Chi-square \\
\hline $\begin{array}{l}\text { Schooling level } \\
\text { Never attended school } \\
\text { Elementary school } \\
\text { Middle school } \\
\text { High school } \\
\text { University }\end{array}$ & $\begin{array}{r}4 \\
33 \\
7 \\
10 \\
4\end{array}$ & $\begin{array}{r}6.9 \\
56.9 \\
12.1 \\
17.2 \\
6.9\end{array}$ & $\begin{array}{r}1 \\
10 \\
3 \\
2 \\
1\end{array}$ & $\begin{array}{r}5.9 \\
58.8 \\
17.6 \\
11.8 \\
5.9\end{array}$ & $\begin{array}{r}2 \\
15 \\
3 \\
5 \\
3\end{array}$ & $\begin{array}{r}7.1 \\
53.6 \\
10.7 \\
17.9 \\
10.7\end{array}$ & $\begin{array}{l}1 \\
8 \\
1 \\
3 \\
0\end{array}$ & $\begin{array}{r}7.7 \\
61.5 \\
7.7 \\
23.1 \\
0.0\end{array}$ & 0.940 & Chi-square \\
\hline $\begin{array}{l}\text { Live alone } \\
\text { Yes } \\
\text { No }\end{array}$ & $\begin{array}{l}11 \\
47\end{array}$ & $\begin{array}{l}19.0 \\
81.0\end{array}$ & $\begin{array}{r}6 \\
11\end{array}$ & $\begin{array}{l}35.3 \\
64.7\end{array}$ & $\begin{array}{r}4 \\
24\end{array}$ & $\begin{array}{l}14.3 \\
85.7\end{array}$ & $\begin{array}{r}1 \\
12\end{array}$ & $\begin{array}{r}7.7 \\
92.3\end{array}$ & 0.110 & Chi-square \\
\hline $\begin{array}{l}\text { Smoking habit } \\
\text { Yes } \\
\text { No }\end{array}$ & $\begin{array}{r}1 \\
57\end{array}$ & $\begin{array}{r}1.7 \\
98.3\end{array}$ & $\begin{array}{r}0 \\
17\end{array}$ & $\begin{array}{r}0 \\
100\end{array}$ & $\begin{array}{r}1 \\
27\end{array}$ & $\begin{array}{r}3.6 \\
96.4\end{array}$ & $\begin{array}{r}0 \\
13\end{array}$ & $\begin{array}{r}0 \\
100\end{array}$ & 0.580 & Chi-square \\
\hline $\begin{array}{l}\text { Alcohol drinking } \\
\text { Never } \\
\text { Once/month or less } \\
\text { 2-4 times/month } \\
\text { 2-3 times/week }\end{array}$ & $\begin{array}{r}40 \\
14 \\
3 \\
1\end{array}$ & $\begin{array}{r}69.0 \\
24.1 \\
5.2 \\
1.7\end{array}$ & $\begin{array}{r}10 \\
5 \\
1 \\
1\end{array}$ & $\begin{array}{r}58.8 \\
29.4 \\
5.9 \\
5.9\end{array}$ & $\begin{array}{r}20 \\
7 \\
1 \\
0\end{array}$ & $\begin{array}{r}71.4 \\
25.0 \\
3.6 \\
0\end{array}$ & $\begin{array}{r}10 \\
2 \\
1 \\
0\end{array}$ & $\begin{array}{r}76.9 \\
15.4 \\
7.7 \\
0.0\end{array}$ & 0.712 & Chi-square \\
\hline
\end{tabular}


Table 2

Association tests and $\mathrm{P}$ values for the variables of subjective health assessment according to the classification of frailty

\begin{tabular}{|c|c|c|c|c|c|c|c|c|}
\hline \multirow{2}{*}{ Variable } & \multicolumn{2}{|c|}{ NF } & \multicolumn{2}{|c|}{ PF } & \multicolumn{2}{|c|}{$\mathbf{F}$} & \multirow{2}{*}{$\mathbf{P}$} & \multirow{2}{*}{ Test } \\
\hline & $\mathbf{n}$ & $\%$ & $\mathbf{n}$ & $\%$ & $\mathbf{n}$ & $\%$ & & \\
\hline Health self-assessment & & & & & & & 0.200 & Chi-square \\
\hline Excellent & 0 & 0.0 & 4 & 14.3 & 0 & 0.0 & & \\
\hline Good & 9 & 52.9 & 10 & 35.7 & 4 & 30.8 & & \\
\hline Fair & 6 & 35.3 & 13 & 46.4 & 8 & 61.5 & & \\
\hline Poor & 2 & 11.8 & 0 & 0.0 & 1 & 7.7 & & \\
\hline Very poor & 0 & 0.0 & 1 & 3.6 & 0 & 0.0 & & \\
\hline Comparison of health with others of the same age & & & & & & & 0.301 & Fisher exact \\
\hline Equal & 3 & 17.6 & 9 & 32.1 & 1 & 7.7 & & \\
\hline Better & 13 & 76.5 & 15 & 53.6 & 9 & 69.2 & & \\
\hline Worse & 1 & 5.9 & 4 & 14.3 & 3 & 23.1 & & \\
\hline Current health $\mathrm{x}$ previous year & & & & & & & $0.016^{*}$ & Fisher exact \\
\hline Equal & 9 & 52.9 & 6 & 21.4 & 1 & 7.7 & & \\
\hline Better & 2 & 11.8 & 4 & 14.3 & 6 & 46.2 & & \\
\hline Worse & 6 & 35.3 & 18 & 64.3 & 6 & 46.2 & & \\
\hline Health care & & & & & & & 0.301 & Fisher exact \\
\hline Excellent & 1 & 5.9 & 5 & 17.9 & 5 & 38.5 & & \\
\hline Good & 11 & 64.7 & 17 & 60.7 & 5 & 38.5 & & \\
\hline Fair & 5 & 29.4 & 5 & 17.9 & 3 & 23.1 & & \\
\hline Poor & 0 & 0.0 & 1 & 3.6 & 0 & 0.0 & & \\
\hline Activity level as compared with that of the previous & & & & & & & $0.010^{*}$ & Fisher exact \\
\hline year & 12 & 70.6 & 9 & 32.1 & 2 & 15.4 & & \\
\hline $\begin{array}{l}\text { Equal } \\
\text { Better }\end{array}$ & 0 & 0.0 & 5 & 17.9 & 1 & 7.7 & & \\
\hline $\begin{array}{l}\text { Better } \\
\text { Worse }\end{array}$ & 5 & 29.4 & 14 & 50.0 & 10 & 76.9 & & \\
\hline
\end{tabular}

NF: non-frail; PF: pre-frail; F: frail. *Statistically significant (95\% confidence).

The subjective assessment of health (Table 2) showed an association of frailty with the following: the comparison of current health with that of the previous year; and the current activity level as compared with that of the previous year. The other items showed no significant differences between the groups.

The elderly had, on average, $3 \pm 1$ distinct comorbidities, and no significant difference was found between the frailty classes $(\mathrm{P}=0.326)$. In isolation, only depression showed a significant association with frailty. Only three (17.6\%) NF elderly reported depression as compared with 15 (53.6\%) $\mathrm{PF}$ elderly and seven $(61.5 \%) \mathrm{F}$ elderly $(\mathrm{P}=0.041)$.

Using the GDS, nine (52.9\%) NF elderly and 20 (71.4\%) PF elderly showed no symptoms of depression. Regarding the F elderly, eight $(61.5 \%)$ had symptoms. However, Fisher exact test showed no significant association between frailty and the presence of depression according to the GDS $(\mathrm{P}=0.118)$.

Regarding the number of medications used (Table 3), a significant difference between the frailty classes was observed $(\mathrm{P}=0.001)$. The NF elderly differed from the PF and F elderly $(\mathrm{P}=0.038$ and $\mathrm{P}=0.001$, respectively). No difference was observed between the PF and F elderly $(\mathrm{P}=0.102)$.
Regarding the BMI (Table 3), the mean for the 58 elderly was $30.00 \pm 6.00 \mathrm{~kg} / \mathrm{m}^{2}$. When assessed in each group, the mean BMI differed significantly between the frailty classes $(\mathrm{P}=0.018)$. The mean BMI of the NF elderly was $27.00 \pm 4.5 \mathrm{~kg} / \mathrm{m}^{2}$, and that of the F elderly was $34.00 \pm 8 \mathrm{~kg} /$ $\mathrm{m}^{2}$. The multiple comparisons evidenced that $\mathrm{PF}$ and $\mathrm{F}$ elderly were similar regarding the $\mathrm{BMI}(\mathrm{P}=0.138)$. On the other hand, the NF elderly differed from both the PF $(\mathrm{P}=0.041)$ and $\mathrm{F}$ $(\mathrm{P}=0.013)$ elderly.

Assessing the relationship between the number of falls reported in the last year and the frailty level, in the F group seven elderly (53.8\%) reported two or more falls, and five $(38.5 \%)$ reported none. On the contrary, in the NF group, only two elderly (11.8\%) reported two or more falls, as compared with 13 (76.5\%) who reported no fall. However, no significant difference between falls and frailty was observed. When comparing the FES-I classification and frailty, the higher percentages of recurring falls were found among the PF (88.2\%) and F (76.9\%) elderly as compared with that among the NF (41.2\%) elderly, but no significant difference was found between non-fallers, fallers and recurring fallers. 
On the contrary, when assessing the FES-I scores (Table 3), the multiple comparisons indicate that the PF and NF elderly were similar $(\mathrm{P}=0.851)$, while the $\mathrm{F}$ elderly differed from both the $\mathrm{PF}(\mathrm{P}=0.014)$ and NF $(\mathrm{P}=0.005)$ elderly.

In addition, the WOMAC index was assessed in its three domains (Table 4). A significant difference was evidenced in the physical function domain $(\mathrm{P}=0.023)$. The multiple comparisons indicated a similarity between the NF and $\mathrm{PF}$ elderly $(\mathrm{P}=0.159)$, as well as between the $\mathrm{PF}$ and $\mathrm{F}$ elderly $(\mathrm{P}=0.365)$. A significant difference was observed between the two extremes: the F and NF elderly $(\mathrm{P}=0.019)$.

Of all the elderly studied, 54 (93\%) had knee OA. The median duration of symptoms was 54 months (P25 $=36$; $\mathrm{P} 75=165)$ for the NF elderly, 60 months (P25 = 48; P75 = 150) for the PF elderly, and 120 months $(\mathrm{P} 25=60 ; \mathrm{P} 75=210)$ for

\section{Table 3}

Comparison of medication use, BMI and FES-I score between frail, pre-frail and non-frail elderly

\begin{tabular}{lcccll}
\hline & NF & PF & F & Statistics & P \\
\hline $\begin{array}{l}\text { Currently used } \\
\text { medications }\end{array}$ & & & & $\mathrm{F}=8.155^{* *}$ & $0.001^{*}$ \\
$\quad$ Mean & 4 & 5 & 7 & & \\
$\quad$ SD & 2 & 2 & 2 & & \\
$\quad$ Median & 3 & 5 & 8 & & \\
BMI & & & & $\chi^{2}=8.021^{* * *}$ & $0.018^{*}$ \\
$\quad$ Mean & 27.45 & 29.94 & 34.03 & & \\
$\quad$ SD & 4.53 & 4.05 & 8.08 & & \\
$\quad$ Median & 25.42 & 29.55 & 34.17 & & \\
FES-I & & & & $\chi^{2}=8.125^{* * *}$ & $0.047^{*}$ \\
$\quad$ Mean & 29 & 31 & 41 & & \\
$\quad$ SD & 9 & 11 & 12 & & \\
$\quad$ Median & 28 & 30 & 44 & & \\
\hline NF: non-frail; PF: pre-frail; F: frail; BMI: body mass index (kg/m²); FES-I (Brasil): Falls Efficacy \\
Scale - International. ${ }^{*}$ Statistically significant (95\% confidence); ${ }^{* *}$ ANOVA: Analysis of variance; \\
***Kruskal-Wallis test.
\end{tabular}

\section{Table 4}

Descriptive statistics, Kruskal-Wallis test, ANOVA, and P values according to the pain, stiffness, and function WOMAC domains

\begin{tabular}{lcccll}
\hline WOMAC & NF & PF & F & Statistics & P \\
\hline Pain & & & & $\mathrm{F}=0.716$ & 0.493 \\
$\quad$ Mean & 34.41 & 35.71 & 43.85 & & \\
SD & 20.30 & 21.89 & 28.81 & & \\
$\quad$ Median & 35.00 & 35.00 & 45.00 & & \\
Stiffness & & & & $\chi^{2}=1.096$ & 0.578 \\
$\quad$ Mean & 38.24 & 47.77 & 39.42 & & \\
$\quad$ SD & 24.40 & 35.85 & 32.21 & & \\
$\quad$ Median & 37.50 & 50.00 & 50.00 & & \\
Function & & & & $\mathrm{F}=4.037$ & $0.023^{*}$ \\
$\quad$ Mean & 30.10 & 42.66 & 52.71 & & \\
$\quad$ SD & 17.80 & 23.55 & 23.03 & & \\
$\quad$ Median & 35.29 & 43.38 & 50.00 & & \\
\hline
\end{tabular}

ANOVA: Analysis of variance; WOMAC: Western Ontario and McMaster Universities; NF: non-frail; PF: pre-frail; F: frail. *Statistically significant ( $95 \%$ confidence). the F elderly. Despite the highest median for the F elderly, no significant difference was observed between the frailty levels $(\mathrm{P}=0.37)$.

The distribution of the NF elderly with knee OA according to the Kellgren-Lawrence grading scale was as follows: grade I, six (37.5\%); grade II, four (25\%); and grade III, six $(37.5 \%)$. That distribution of the PF elderly was as follows: grade I, five (20\%); grade II, seven (28\%); and grade III, $13(52 \%)$. Regarding the F elderly, that distribution was as follows: grade I, two (15.4\%); grade II, six (46.2\%); grade III, three (23.1\%); and grade IV, two (15.4\%). The Fisher exact test showed no significant association between frailty and the Kellgren-Lawrence grading scale.

Only seven elderly in the sample (12\%) were diagnosed with hip OA, with a median duration of symptoms of 90 months $(\mathrm{P} 25=12 ; \mathrm{P} 75=60)$ for the NF, of 96 months $(\mathrm{P} 25=24)$ for the PF, and of 96 months for the F elderly. No significant difference was observed between that variable and the frailty levels $(P=0.775)$. In addition, the Kellgren-Lawrence grading scale showed no significant differences between the frailty levels $(\mathrm{P}=1.00)$.

\section{DISCUSSION}

This study aimed at assessing the characteristics of the elderly with knee and/or hip OA, focusing on the frailty syndrome.

A significantly higher number of women comprised our sample, and the first explanation for that might be the source of the sample data, in which women were the majority (404 women and 203 men). In addition, it has been reported that knee $\mathrm{OA},{ }^{3,18}$ which also comprised most of the study sample, is more prevalent in women. Another aspect relates to the question that led us to those elderly, regarding their diagnosis with arthritis or rheumatism by a physician. Such question may represent a bias, because studies have shown that women seek medical care more often than men do, ${ }^{19,20}$ and, thus, it is believed that women are more likely to have diseases diagnosed by a physician as compared with men.

The percentage of the F elderly found (22.41\%) differs from those in the literature. Fried et al. ${ }^{6}$ have reported $6.9 \%$ of F elderly. Cesari et al. ${ }^{10}$ have reported $8.8 \%$, and Santos ${ }^{21}$ has found $13.2 \%$ of those individuals. Even when compared with the findings by Santos-Eggimann et al., ${ }^{22}$ who have assessed frailty in 10 European countries and have found a mean of $17 \%$ of $F$ elderly, the prevalence found in the present study remains greater. It is believed that the fact that this study's sample comprised only elderly with OA might 
have influenced the results, since a significant association between $\mathrm{OA}$ and frailty has already been reported. ${ }^{10,11}$ The higher number of women in the present study might also be an explanation, since there is evidence that they tend to be more frail then men. ${ }^{6,23}$ Nevertheless, the prevalence of frail female elderly in the Cardiovascular Health Study (CHS) was 7.3\% ${ }^{6}$ and in The Women's Health and Aging Studies (WHAS), 11.3\% ${ }^{23}$ Another explanation would be Brazilian's ethnic mixture since its origin. In the study by Cesari et al., ${ }^{10}$ while Switzerland and Sweden had 5.8\% and $8.6 \%$ of F elderly, respectively, Italy and Spain had $23 \%$ and $27.3 \%$, respectively. ${ }^{22}$ In an attempt to explain those differences, a study with Afro-Americans (AAM) and European-Americans (EA) has assessed the percentage of elderly in each frailty group using two different cut-off points: one unadjusted for ethnicity and the other adjusted for ethnicity. ${ }^{24}$ When the unadjusted cut-off point was used, a greater percentage of frail individuals was found in the AAM group. That difference disappeared when the cut-off point adjusted for each ethnicity was used. At least part of that difference is believed to occur due to differences in the BMI and height among ethnicities, variables used to establish cut-off points for grip strength and walking speed, respectively. ${ }^{24}$ Along that same line, Santos, ${ }^{21}$ assessing Brazilian older adults, has also reported a difference among the frailty groups after adjusting the Fried's cut-off points for the population studied. While for the original cut-off points the prevalences of frailty and PF were $13.27 \%$ and $49.29 \%$, respectively, after adjusting, both groups showed a reduction, passing to $10.6 \%$ and $43.36 \%$ for $\mathrm{F}$ and $\mathrm{PF}$ groups, respectively. ${ }^{21}$ However, even if the difference in the cut-off point explains part of the present study's findings, the frailty prevalence, as compared with the unadjusted data of Santos, ${ }^{21}$ remains higher.

Regarding the subjective health assessment, the items analyzing the current health status and activity level as compared with those of the previous year showed an association with frailty. The number of the F elderly reporting worsening of their health status as compared with that of the previous year was the same of those reporting an improvement. On the contrary, in the PF group, most elderly reported worsening of their health status as compared with that of the previous year. Regarding the current physical activity level as compared with that of the previous year, both the F and PF elderly reported worsening. The crosssectional characteristic of this study does not allow stating the causes of those changes, but, based on the literature, one can speculate about some of them.
Health self-assessment is known to predict, in a robust and consistent way, mortality and functional decline, ${ }^{25}$ and frailty has already been observed to relate to those aspects. Thus, the first justification could be the dynamic characteristic of frailty, ${ }^{26}$ as follows: the elderly who currently report worsening could be, in the previous year, in another frailty category, considering the frailty phenotype. ${ }^{6}$ That, however, does not explain the percentage of the $\mathrm{F}$ elderly reporting an improvement in their health status. The functional capacity has a floating characteristic, ${ }^{27,28}$ which might explain the reported improvement by part of the F elderly, who, despite remaining in the same frailty category, might have moved to a better level of functional capacity, and, thus, acquired a better perception of health. It might still explain the worsening previously described, since the transition can occur in both directions. In addition to the questions related to frailty, pain in OA has also floating characteristics, ${ }^{29}$ which can justify part of the changes in self-perception.

Contrary to that reported in the literature, $, 6,11,30$ this study showed no significant difference in the number of comorbidities among the frailty groups (the mean number was the same in all three groups). Although this does not corroborate the findings of other studies, ${ }^{6,11,30}$ the lack of association between comorbidity and frailty emphasizes the concept that frailty is a distinct clinical syndrome. ${ }^{6,7}$ On the other hand, the fact that $\mathrm{OA}$ is a disease with a high comorbidity rate ${ }^{31,32}$ might have hindered the identification of differences among the groups.

Reporting depression diagnosed by a physician was associated with frailty. However, when the presence of depressive symptoms was assessed by the GDS instrument, ${ }^{16}$ no significant difference was observed, although the $\mathrm{F}$ group showed a higher prevalence. It is believed that part of the elderly who answered "yes" to the question "Have you been diagnosed with depression by a physician?" might have no more symptoms of depression because of the treatment, and, thus, might not have been screened as positive in the GDS. ${ }^{16}$ Other studies ${ }^{6,11,30}$ have reported an association between frailty and symptoms of depression. Two of those studies have excluded from their samples the elderly on antidepressants. ${ }^{6,30}$ Thus, the elderly of those studies who could have depression were those not being treated, which might have allowed the instruments used (Center for Epidemiological Studies-Depression - CES-D and GDS) to detect a greater number of cases, and the association between depression and frailty could be perceived. ${ }^{6,30}$ Thus, we believe that the non-exclusion of the elderly with depression from 
the present study made the criterion "depression diagnosed by a physician" more sensitive to demonstrate the association between depression and frailty as compared with the GDS.

Another important aspect well-described in the literature is that $\mathrm{OA}$, depression and frailty, in isolation, are risk factors for incapacity. ${ }^{4,6,733,34}$ In addition, depression has been related to worse functioning in the elderly with OA. ${ }^{35,36}$ The present study, in which all the elderly have OA, showed that the F elderly are even more depressed than the NF elderly. Thus, the elderly diagnosed with simultaneous OA, depression and frailty should be carefully considered, because they are at higher risk of developing future incapacity.

Although this study found no association between comorbidity and frailty, it showed that the F elderly use a significantly greater number of medications as compared with the NF elderly. One explanation for that finding could be that the severity rather than the number of comorbidities might be more associated with frailty. The higher number of medications might be one way of reflecting the severity of comorbidities. Another aspect reported in the literature is that some adverse effects of the medications can contribute to frailty. ${ }^{37}$ However, the present study does not allow confirming those hypotheses, and further studies are required to better clarify that question.

The elderly of the present study tended towards obesity, which is a known risk factor for the development and progression of $\mathrm{OA}^{38,39}$ and has effects on the progression of the functional limitation and incapacity of the elderly with that condition. ${ }^{4,40}$ Some studies have evidenced an association between obesity and frailty, ${ }^{41,42}$ as well as a greater risk of incapacity in the elderly with sarcopenic obesity. ${ }^{41,43}$ When assessed according to frailty group, the BMI proved to be significantly greater in the PF and $\mathrm{F}$ groups than in the NF group. Those findings suggest that the elderly with OA and frailty have a greater tendency towards obesity, and, in the presence of the three conditions, a higher risk for functional limitation.

The assessment of the number of falls in the last 12 months showed no significant difference among the groups. However, although non-significant, the F group showed a tendency towards a greater percentage of elderly with at least two falls, and recurring falls are the ones that most predict negative outcomes. ${ }^{44}$ The results of the present study differ from those of other studies, ${ }^{6,30}$ which show an association between fall and frailty. Because knee and/or hip OA is a predisposing factor to falls, that may have been one of the reasons for not finding an association with frailty in this study, which strengthens the multifactorial character of the etiology of falls. ${ }^{45}$ Another question is that the elderly can both forget their falls and neglect their occurrence, ${ }^{44}$ which influences the results obtained in the investigation.

The outcome "fall" was also assessed by use of the FES-I-Brasil. ${ }^{15}$ When classified as non-fallers, fallers and recurring fallers, no significant difference was observed among the groups, although recurrent falls were more common in the F and PF groups. When the total scores were used, an association was found between the F group and higher scores, evidencing that the elderly with OA and frailty are more concerned about falling, indicating a lower fallrelated self-efficacy. An explanation for those apparently discordant results would be that the original cut-off points for the classification of non-fallers, fallers and recurring fallers in the sample of the adaptation study of FES-I to Brazil do not have the same sensitivity in a sample in which all the elderly have knee and/or hip OA - thus, the total score might be more appropriate for the present study. A tendency towards a greater percentage of elderly classified as recurring fallers in the F and PF groups is observed, as is an association between F elderly and worse fall-related self-efficacy when using the total score of the FES-I. Thus, it is worth noting that both worse fall-related self-efficacy and recurring falls might lead to physical activity restriction and worse quality of life. ${ }^{15,46}$

Pain, stiffness and physical function were assessed by use of the WOMAC questionnaire,,$^{14}$ and only physical function showed an association with frailty, having the F group the greatest, and thus worse, mean. This shows that the F elderly with OA of this sample have worse function and might be at a higher risk for progressing with incapacities and dependence than the NF elderly with OA.

Although no significant difference was observed for the "pain" domain, the F elderly had a worse mean than the other groups. It has been reported that pain in OA has a floating characteristic. ${ }^{29}$ The WOMAC sensitive to show any association between pain and frailty might have been low, because it refers to pain only in the last 72 hours. Because the OA pain is related to functional changes, fatigue, mood swings, worse quality of life, reduced independence, and worse perception of health, ${ }^{47-49}$ it is believed that studies assessing OA pain and frailty in a more detailed way might bring more relevant information for the clinical practice.

The duration of symptoms and radiographic changes, both in the elderly with knee OA and in those with hip OA, showed no significant differences between the frailty groups. Radiographic changes in the elderly with OA do not show, or have a weak association with, functional aspects. ${ }^{50}$ The 
present study assessed whether the radiographic changes were associated with frailty, but that association could not be evidenced. However, the duration of symptoms, although not yet well-defined in the literature, seems to be significant for the functional changes. ${ }^{50}$ In addition, it is believed that the duration of symptoms to be also significant for frailty, and, although this study shows the opposite, another study with similar numbers of elderly with initial and older OA symptoms can better clarify that aspect.

\section{CONCLUSION}

Of the most relevant results, the following stand out: the elderly with OA and frailty in this sample use a greater number of medications, are more obese and depressed, and have worse fall-related self-efficacy and physical function. Although this study found no significant difference among the groups regarding pain and symptom duration, such aspects should be further assessed in future studies. 


\section{REFERENCES}

1. Parahyba MI, Simões CCS. Disability prevalence among the elderly in Brazil. Ciênc Saúde Coletiva 2006; 11(4):967-74.

2. Altman RD. Clinical Features of Osteoarthritis. In: Hochberg MC (ed.). Rheumatology. 5.ed. Philadelphia: Elsevier; 2011.

3. Seda H, Fuller R. Osteoartrite. Reumatologia Diagnóstico e Tratamento. 3.ed. Rio de Janeiro: Guanabara Koogan; 2008.

4. McDonough CM, Jette AM. The contribution of osteoarthritis to functional limitations and disability. Clin Geriatr Med 2010; 26(3):387-99.

5. Figueiredo Neto EM, Queluz TT, Freire BF. Physical activity and its association with quality of life in patients with osteoarthritis. Rev Bras Reumatol 2011; 51(6):544-9.

6. Fried LP, Tangen CM, Walston J, Newman AB, Hirsch C, Gottdiener J et al. Frailty in older adults: evidence for a phenotype. J Gerontol A Biol Sci Med Sci 2001; 56(3):M146-56.

7. Fried LP, Ferrucci L, Darer J, Williamson JD, Anderson G. Untangling the concepts of disability, frailty, and comorbidity: implications for improved targeting and care. J Gerontol A Biol Sci Med Sci 2004; 59(3):255-63.

8. Rockwood K, Stadnyk K, MacKnight C, McDowell I, Hébert R, Hogan DB. A brief clinical instrument to classify frailty in elderly people. The Lancet 1999; 353(9148):205-6.

9. Rockwood K, Andrew M, Mitnitski A. A comparison of two approaches to measuring frailty in elderly people. J Gerontol A Biol Sci Med Sci 2007; 62(7):738-43.

10. Cesari M, Leeuwenburgh C, Lauretani F, Onder G, Bandinelli S, Maraldi $\mathrm{C}$ et al. Frailty syndrome and skeletal muscle: results from the Invecchiare in Chianti study. Am J Clin Nutr 2006; 83(5):1142-8.

11. Drey M, Wehr H, Wehr G, Uter W, Lang F, Rupprecht R et al. The frailty syndrome in general practitioner care: a pilot study. Z Gerontol Geriatr 2011; 44(1):48-54.

12. Altman R, Asch E, Bloch D, Bole G, Borenstein D, Brandt $\mathrm{K}$ et al. Development of criteria for the classification and reporting of osteoarthritis. Classification of osteoarthritis of the knee. Diagnostic and Therapeutic Criteria Committee of the American Rheumatism Association. Arthritis Rheum 1986; 29(8):1039-49.

13. Brucki SM, Nitrini R, Caramelli P, Bertolucci PH, Okamoto IH. Suggestions for utilization of the mini-mental state examination in Brazil. Arq Neuropsiquiatr 2003; 61(3B):777-81.

14. Fernandes MI. Tradução e validação do questionário de qualidade de vida específico para osteoartrose WOMAC (WesternOntario McMaster Universities) para a língua portuguesa [dissertação]. São Paulo: Universidade Federal de São Paulo; 2003. 103p.
15. Camargos FF, Dias RC, Dias JM, Freire MT. Adaptação transcultural e avaliação das propriedades psicométricas da Falls Efficacy ScaleInternational em idosos Brasileiros (FES-I-BRASIL). Rev Bras Fisioter 2010; 14(3):237-43.

16. Almeida OP, Almeida SA. Confiabilidade da Versão Brasileira da Escala de Depressão em Geriatria Versão Reduzida. Arq Neuropsiquiatr 1999; 57(2B):421-6.

17. Kellgren JH, Lawrence JS. Radiological assessment of osteoarthrosis. Ann Rheum Dis 1957; 16(4):494-502.

18. Felson DT, Naimark A, Anderson J, Kazis L, Castelli W, Meenan RF. The prevalence of knee osteoarthritis in the elderly. The Framingham Osteoarthritis Study. Arthritis Rheum 1987; 30(8):914-8.

19. Boing AF, Matos IB, Arruda MP, Oliveira MC, Njaine K. Prevalência de consultas médicas e fatores associados: um estudo de base populacional no sul do Brasil. Rev Assoc Med Bras 2010; 56(1):41-6.

20. Pinheiro RS, Viacava F, Travassos C, Brito AS. Gênero, morbidade, acesso e utilização de serviços de saúde no Brasil. Ciênc Saúde Coletiva 2002; 7(4):687-707.

21. Santos EGS. Perfil de fragilidade em idosos comunitários de Belo Horizonte: um estudo transversal [dissertação]. Belo Horizonte: Universidade Federal de Minas Gerais; 2008. 98p.

22. Santos-Eggimann B, Cuénoud P, Spagnoli J, Junod J. Prevalence of frailty in middle-aged and older community-dwelling Europeans living in 10 countries. J Gerontol A Biol Sci Med Sci 2009; 64(6):675-81.

23. Bandeen-Roche K, Xue QL, Ferrucci L, Walston J, Guralnik JM, Chaves P et al. Phenotype of frailty: characterization in the women's health and aging studies. J Gerontol A Biol Sci Med Sci 2006; 61(3):262-6.

24. Espinoza SE, Hazuda HP. Frailty in older Mexican-American and European-American adults: is there an ethnic disparity? J Am Geriatr Soc 2008; 56(9):1744-9.

25. Lima-Costa MF, Firmo JO, Uchôa E. A estrutura da autoavaliação da saúde entre idosos: projeto Bambuí. Rev Saúde Pública 2004; 38(6):827-34.

26. Gill TM, Gahbauer EA, Allore HG, Han L. Transitions between frailty states among community-living older persons. Arch Intern Med 2006; 166(4):418-23.

27. Woodhouse KW, O'Mahony MS. Frailty and ageing. [comment on Age Ageing 1997; 26(4):315-8.] Age Ageing 1997; 26(4):245-6.

28. Hardy SE, Dubin JA, Holford TR, Gill TM. Transitions between states of disability and independence among older persons. Am J Epidemiol 2005; 161(6):575-84.

29. Gooberman-Hill R, Woolhead G, Mackichan F, Ayis S, Williams S, Dieppe P. Assessing chronic joint pain: lessons from a focus group study. Arthritis Rheum 2007; 57(4):666-71.

30. Woods NF, LaCroix AZ, Gray SL, Aragaki A, Cochrane BB, Brunner RL et al. Frailty: emergence and consequences in women aged 65 and older in the Women's Health Initiative Observational Study. J Am Geriatr Soc 2005; 53(8):1321-30.

31. van Dijk GM, Veenhof C, Schellevis F, Hulsmans H, Bakker JP, Arwert $\mathrm{H}$ et al. Comorbidity, limitations in activities and pain in patients with osteoarthritis of the hip or knee. BMC Musculoskelet Disord 2008; 9:95.

32. Leite AA, Costa AJ, Lima BA, Padilha AV, Albuquerque EC, Marques $\mathrm{CD}$. Comorbidities in patients with osteoarthritis: frequency and impact on pain and physical function. Rev Bras Reumatol 2011; 51(2):118-23. 
33. Lin YC, Davey RC, Cochrane T. Tests for physical function of the elderly with knee and hip osteoarthritis. Scand J Med Sci Sports 2001; 11(5):280-6.

34. Wilkins VM, Kiosses D, Ravdin LD. Late-life depression with comorbid cognitive impairment and disability: nonpharmacological interventions. Clin Interv Aging 2010; 5:323-31.

35. Dekker J, van Dijk GM, Veenhof C. Risk factors for functional decline in osteoarthritis of the hip or knee. Curr Opin Rheumatol 2009; 21(5):520-4.

36. Machado GP, Gignac MA, Badley EM. Participation restrictions among older adults with osteoarthritis: a mediated model of physical symptoms, activity limitations, and depression. Arthritis Rheum 2008; 59(1):129-35.

37. Weiss CO. Frailty and chronic diseases in older adults. Clin Geriatr Med 2011; 27(1):39-52.

38. Blagojevic M, Jinks C, Jeffery A, Jordan KP. Risk factors for onset of osteoarthritis of the knee in older adults: a systematic review and meta-analysis. Osteoarthritis Cartilage 2010; 18(1):24-33.

39. Sowers MF, Yosef M, Jamadar D, Jacobson J, Karvonen-Gutierrez C, Jaffe M. BMI vs. body composition and radiographically defined osteoarthritis of the knee in women: a 4-year follow-up study. Osteoarthritis Cartilage 2008; 16(3):367-72.

40. Ettinger WH, Davis MA, Neuhaus JM, Mallon KP. Long-term physical functioning in persons with knee osteoarthritis from NHANES. I: Effects of comorbid medical conditions. J Clin Epidemiol 1994; 47(7):809-15.

41. Baumgartner RN. Body composition in healthy aging. Ann N Y Acad Sci 2000; 904:437-48.

42. Blaum CS, Xue QL, Michelon E, Semba RD, Fried LP. The association between obesity and the frailty syndrome in older women: the Women's Health and Aging Studies. J Am Geriatr Soc 2005; 53(6):927-34.
43. Baumgartner RN, Wayne SJ, Waters DL, Janssen I, Gallagher D, Morley JE. Sarcopenic obesity predicts instrumental activities of daily living disability in the elderly. Obes Res 2004; 12(12):1995-2004.

44. Ferrucci L, Guralnik JM, Studenski S, Fried LP, Cutler GB Jr, Walston JD. Designing randomized, controlled trials aimed at preventing or delaying functional decline and disability in frail, older persons: a consensus report. J Am Geriatr Soc 2004; 52(4):625-34.

45. Berry SD, Miller RR. Falls: epidemiology, pathophysiology, and relationship to fracture. Curr Osteoporos Rep 2008; 6(4):149 -54.

46. Lachman ME, Howland J, Tennstedt S, Jette A, Assmann S, Peterson EW. Fear of falling and activity restriction: the survey of activities and fear of falling in the elderly (SAFE). J Gerontol B Psychol Sci Soc Sci 1998; 53(1):43-50.

47. Allen KD, Renner JB, Devellis B, Helmick CG, Jordan JM. Osteoarthritis and sleep: the Johnston County Osteoarthritis Project. J Rheumatol 2008; 35(6):1102-7.

48. Hawker GA, Stewart L, French MR, Cibere J, Jordan JM, March L et al. Understanding the pain experience in hip and knee osteoarthritis - an OARSI/OMERACT initiative. Osteoarthritis Cartilage 2008; 16(4):415-22.

49. Hutchings A, Calloway M, Choy E, Hooper M, Hunter DJ, Jordan JM et al. The Longitudinal Examination of Arthritis Pain (LEAP) study: relationships between weekly fluctuations in patient-rated joint pain and other health outcomes. J Rheumatol 2007; 34(11):2291-300.

50. van Dijk GM, Dekker J, Veenhof C, van den Ende CH; Carpa Study Group. Course of functional status and pain in osteoarthritis of the hip or knee: a systematic review of the literature. Arthritis Rheum 2006; 55(5):779-85. 